\title{
Die nuwe Psalmomdigting: Die Messias
}

\author{
weggelaat? $^{1}$
}

\author{
H F Van Rooy \\ Skool vir Bybelwetenskappe en Bybeltale \\ Noordwes-Universiteit (Potchefstroomkampus)
}

\begin{abstract}
The new Psalter in Afrikaans: Was the Messiah omitted?

In 2001 a new Afrikaans metrical Psalter was published. Although beging severely criticised in som circles, it is being used by a number of churches. One of the major criticisms is that it omitted the Messiah from the Psalter, the implication being the way in which the so-called Messianic Psalms were treated in this Psalter, is cause for concern. This article discusses this criticism, provides a framework for dealing with the Messianic Psalms and evaluates the criticism. This criticism can not be regarded as valid. This Psalter tried to reflect the original context of the individual Psalms, refraining from using the New Testament's use of the Psalms as a decisive factor for determining the original meaning.
\end{abstract}

\section{INLEIDING}

In 2001 het 'n nuwe Psalmomdigting in Afrikaans verskyn. Dit vorm deel van die Liedboek van die Kerk, wat in 2001 verskyn het en wat in gebruik is by die Nederduitse Gereformeerde Kerk en die Nederduitsch Hervormde Kerk van Afrika. Die nuwe Psalmomdigting is ook opgeneem, saam met die bekende 1936-Psalmberyming, in die nuwe Psalmboek van die Gereformeerde Kerke in Suid-Afrika. Die Nuwe Omdigting is in baie kerke met groot blydskap in gebruik geneem, terwyl dit in ander kringe weer 'n sterk negatiewe reaksie ontlok het. Verskeie punte van kritiek kom telkens na vore teen die Nuwe Omdigting. Dit raak onder ander die manier waarop die verskillende Godsname weergegee is, verkorting van sekere Psalms en die weglating van die Messias in die Nuwe Omdigting. Hierdie artikel gaan alleen let op

\footnotetext{
${ }^{1}$ Prof Andries Breytenbach en ek het vir etlike jare saam gedien op die interkerklike kommissie wat aan die nuwe Psalmomdigting gewerk het. Ons was ook twee van die drie OuTestamentici wat op ' $n$ kleiner werkgroep van dertien persone gedien het. In die lig hiervan word hierdie artikel oor 'n aspek van die nuwe Psalmomdigting aan hom opgedra, met erkenning vir sy vriendskap en vakmanskap.
} 
laasgenoemde saak om die vraag te beantwoord of die nuwe Psalmomdigting wel die Messias weglaat, soos wat beweer word. In die bespreking van voorbeelde gaan toegespits word op Psalm 2 en 110, twee Psalms wat deur die geskiedenis en tot vandag toe wyd as Messiaanse Psalms beskou word.

\section{DIE BESWAAR TOEGELIG}

Die saak van die interpretasie van die sogenaamde Messiaanse Psalms is natuurlik al baie oud, maar dit het in Suid-Afrika nuwe belangstelling gekry na die verskyning van die 1983 Afrikaanse Bybelvertaling, en veral die nuwe Psalmomdigting in 2001. Die saak kom veral na vore in die gebruik of weglating van hoofletters om die Psalm direk aan die Messias te verbind. As voorbeeld kan verwys word na enkele gedeeltes uit Psalm 2.

\section{3/53-Vertaling}

2. Die konings van die aarde staan gereed, en die vorste hou saam raad teen die HERE en sy Gesalfde en sê:

\section{6. Ék tog het my Koning gesalf oor Sion,} my heilige berg.

\section{Ek wil vertel van die besluit: Die HERE} het aan My gesê: $U$ is my Seun, vandag het Ek self $U$ gegenereer.

11. Dien die HERE met vrees, en juig met bewing.

12. Kus die Seun, dat Hy nie toornig word en julle op die weg vergaan nie; want gou kan sy toorn ontvlam. Welgeluksalig is almal wat by Hom skuil.

\section{3-Vertaling}

2. Die konings van die aarde is in opstand, die leiers span saam teen die Here en teen sy gesalfde en sê:

6. "Dit is Ek wat hom as my koning gesalf het, op Sion, my heilige berg."

7. Ek wil vertel wat die Here aangekondig het. Hy het vir my gesê: "Jy is my seun, van vandag af is Ek jou Vader.

11. Julle moet die Here met ontsag dien, Hom met vrees en bewing toejuig.

12. en Hom onderdanig wees, sodat Hy nie toornig word en julle op die pad omkom nie, want sy toorn ontvlam hou. Dit gaan goed met almal wat by Hom skuiling soek.

Die Messiaanse interpetasie van die Ou Vertaling word duidelik gemaak deur die hoofletters by Gesalfde (vers 2), Koning (vers 6), U (2 keer) en Seun (vers 7) en Seun, Hy en Hom in vers 12. Dit is duidelik dat die Nuwe Vertaling ' $n$ ander weg opgegaan het in die interpretasie. In vers 12 is op voet van die voorstel in die Biblia Hebraica Stuttgartensia 'n ander lesing aanvaar om die tekskritiese probleem in die vers op te los, waardeur die problematiese frase "Kus die Seun" met sy Aramese woord vir "seun" weggeval het. 
Die Ou Beryming volg die voorbeeld van die Ou Vertaling, met duidelike Messiaanse aanduidings in strofes 1 en 3-6, terwyl die Nuwe Omdigting die voorbeeld van die Nuwe Vertaling volg.

Verskeie persone wat beswaar teen die Nuwe Omdigting het, het hieroor geskryf. Tot op datum het daar egter nog nie uit die kring 'n behoorlike wetenskaplike studie die lig gesien nie, maar daar is baie geskryf in populêre blaaie. As voorbeeld van sulke besware, gaan na die standpunte van enkele skrywers verwys word. Die standpunte is veral gestel in drie blaaie wat in die kringe van die Gereformeerde Kerke in Suid-Afrika versprei word, naamlik Die Kerkblad, Die Kerkpad en Waarheid en Dwaling. Lesers van veral laasgenoemde twee blaaie was baie ongelukkig met die besluit van die Sinode van die Gereformeerde Kerke in Suid-Afrika in 2003 om die Nuwe Omdigting te aanvaar en vir gebruik aan te beveel, asook om die Nuwe Omdigting saam met die Ou Beryming in een Psalmboek uit te gee.

Dit gebeur ook meermale dat persone wat beswaar het teen die weglating van Messiaanse verwysing, hulle baie sterk hieroor uitspreek. Meijer (2002) aanvaar dat die Psalms direkte messiaanse profesieë bevat. Hy sê (Meijer 2002:9) dat die nuwe navorsing waarop die Nuwe Omdigting berus, 'n herhaling is van "die ou Joodse dwaling, 'n stokou kettery in die splinternuwe baadjie van Die Bybel in Praktyk. Vir hom is die Psalmboek 'n Christus-profesie (Meijer 2002:9), terwyl die Nuwe Omdigting volgens hom deur die teologie gedra word wat in die gedeelte oor die Psalms in Die Bybel in Praktyk na vore kom. Sy konklusie is baie sterk (Meijer 2002:10) "In die lig van die bostaande moet ons die Cloete-beryming afwys om ons Skrifgeloof te behou."

'n Persoon wat hom meemale baie sterk teen die Nuwe Omdigting uitgespreek het, is V E d'Assonville (snr). 'n Groot beswaar, wat hy telkens noem, is dat dele van die Bybel in die Nuwe Omdigting weggelaat word (d'Assonvile 2002a:4). Hy gee dan 'n hele lys van weglatings van Christus. Van Psalm 2:7 sê hy dat dit in die geheel in die Nuwe Omdigting weggelaat is (d'Assonville 2002a:5-6). Nog weglatings kom volgens hom onder andere voor in Psalm 31:6, 41:10, 47:6 en talle ander plekke. Ten opsigte van die Nuwe Omdigting se hantering van Psalm 110 is hy baie krities (d'Assonville 2002a:6). Sy kritiek is dat die Godsnaam Adonai in vers 1 vervang is met "my koning" en dat die uitdrukking "vyande as voetbank van u voete" 'n nuwe vertolking kry, anders as wat by die apostels in Handelinge aangetref word. In 'n volgende artikel in 2002 stel d'Assonville (2002b:3) dat met die keuse vir of teen die Nuwe Omdigting dit 'n saak geword het van 'n radikale keuse: "Die Woord van God òf die woord van mense!" Die ergste wat die Nuwe Omdigting gedoen het, was om met opset Christus uit die Psalms te verwyder 
(d'Assonville 2002b:4). Weer word 'n lys van gedeeltes aangegee, wat grotendeels ooreenkom met die lys in die vorige artikel waarna verwys is. Wat Psalm 110 betref, sê hy (d'Assonville 2002b:5-6) dat die Godheid van Christus hierdeur verwerp word. As nie aanvaar word dat Psalm 110 'n Messiaanse Psalm is nie, word ' $n$ valse leer verkondig (d'Assonville 2002b:6).

In Die Kerkpad van Januarie 2004 het twee artikels verskyn na aanleiding van die ingebruikneming van die nuwe Psalmboek van die Gereformeerde Kerke in Suid-Afrika, met die Nuwe Omdigting as deel daarvan. Van der Dussen (2004:1) sien die dag van die ingebruikneming van die nuwe Psalmboek as 'n dag van beslissing in die GKSA. Hy betreur dit dat die Sinode van 2003 die Nuwe Omdigting goedgekeur het, al het hulle geweet van die weglating van Christus in die Psalms. Hy verwys spesifiek na Psalm 2, 45, 107 en 110 as uitdruklike Christuspsalms. Hy oordeel dat die Nuwe Afrikaanse Vertaling die weg vir hierdie omdigting voorberei het (Van der Dussen 2004:2). In dieselfde uitgawe van Die Kerkpad oordeel d'Assonvile (2004) baie negatief oor die besluit van die Sinode van die GKSA in 2003 om die Nuwe Omdigting te aanvaar. Hy verwys na 15 November 1812 as die dag waarop die Evangeliese Gesangboek in gebruik geneem is. Hierdie gebeure bestempel hy as "die grootste ramp wat die Gereformeerde kerke in die 19de eeu in Suid-Afrika getref het" (d'Assonville 2004:1). 11 Februarie 1859 was vir hom weer 'n dag van 'n besondere reformasie, onder andere weens die verwerping van "mensgemaakte gesange en die mens se idees sonder die Woord" (d'Assonville 2004:3). Hierteenoor staan die besluit van die Sinode van 2003. Die teologie wat agter die Nuwe Omdigting lê, is vals en onbybels (d'Assonville 2004:4).

Op dieselfde dag (en die vorige dag) as wat die GKSA se nuwe Psalmboek in gebruik geneem is, het mense uit die GKSA 'n ander vergadering gehou om hulle ontsteltenis met ontwikkelinge in die GKSA te bespreek. In 'n verslag van die byeenkoms verwys Momberg (2004) ook na die Psalms, en spesifiek Psalm 110:1. Volgens hom bevat die nuwe Psalmbundel 'n "menslike ontwerp van 'n godheid" (Momberg 2004:26). Hy oordeel dat die miskenning van Christus in Psalm 110 die belydenis van die Triniteit in gedrang bring (Momberg 2004:27).

'n Finale voorbeeld uit die kring van die GKSA word aangetref in die artikel van d'Assonville (jnr), Kayayan en Schulze (2004). Ook vir hulle weeg die saak van die Messiaanse Psalms baie swaar. Christus se uitleg moet volgens hulle deurslaggewend wees vir die verstaan van die Psalms (d'Assonville, Kayayan \& Schulze 2004:32). Psalm 110 is ook vir hulle 'n belangrike voorbeeld. Hulle vra waarom die deputate die grondteks van Psalm 110:1 verander het (d'Assonville, Kayayan \& Schulze 2004:32). Hulle dui aan 
dat die grondteks gelees het "Dit het Jhwh (die HERE) vir my Here gesê." Volgens die Omdigting, wat "my Here" met "my koning" vervang het, is hier dan nie 'n profesie van Christus ter sprake nie. Hulle meen ook dat die deputate se standpunt dat die Messiaanse karakter van 'n gedeelte 'n saak van interpretasie is, "stry teen die werklike stand van sake en ons gereformeerde geloof, naamlik: die Bybel is die openbaring van God" (d'Assonville, Kayayan \& Schulze 2004:32). Hulle verwys ook daarna dat Psalm 31:6 in die Omdigting heeltemal weggelaat is. Die probleem is volgens hulle dat die Nuwe-Testamentiese uitsprake nie as gesaghebbend aanvaar word nie, wat die hele Skrifbeskouing van die Omdigting problematies maak (d'Assonville, Kayayan \& Schulze 2004:33). Hulle oordeel dus dat die NuweTestamentiese verstaan van die Psalms deurslaggewend moet wees vir die verstaan van die Psalms in die Ou Testament, omdat die Gees as primêre Outeur tog nie Homself kan weerspreek nie.

Alhoewel die saak van die Messiaanse Psalms baie opslae in die GKSA gemaak het, het dit ook wyer aandag geniet. In 'n boekie van ds Danie Haasbroek, 'n predikant in die Nederduitse Gereformeerde Kerk, word die saak ook hanteer uit dieselfde hoek as die persone hierbo genoem. Reeds in sy voorwoord konfronteer hy (Haasbroek 2003: Voorwoord) sy lesers met die kernprobleem: "Is u bewus daarvan dat Jesus nie meer in die Messiaanse Psalms in die nuwe Psalmberyming te sien is nie?" Ook hy vind dat die tendens wat in die Nuwe Afrikaanse Bybelvertaling begin het, in die Nuwe Omdigting voortgesit is (Haasbroek 2003:2-3). In baie Psalms is Jesus wegberym, wat hy laat blyk uit 'n vergelyking van die Ou Beryming met die Nuwe Omdigting. Hy verwys veral na Psalm 2, 45 en 110 (Haasbroek 2003:34). Anders as die vorige persone verwys hy nie bloot na die weglating van die Messias of Christus uit die Psalms nie, maar van Jesus (Haasbroek 2003:5). Hy gaan so ver as om te sê dat baie mense in die tyd van die Ou Testament Jesus as persoon ontmoet het (Haasbroek 2003:6). Hy aanvaar ook nie die gedagte dat die Messiaanse gedeeltes indirek-Messiaans kan wees nie. Volgens hom het die Messiaanse Psalms en profesieë direk na Jesus verwys (Haasbroek 2003:13).

\section{DIE MESSIAANSE INTERPRETASIE VAN DIE PSALMS IN DISKUSSIE}

Dit is uiteraard onmoontlik om 'n volledige oorsig te gee oor die geskiedenis van die Messiaanse interpretasie van sekere Psalms. Dit is egter uit die geskiedenis baie duidelik dat 'n hele aantal, soms alle, Psalms Messiaans geïnterpreteer is. So bied Hay (1973) byvoorbeeld 'n baie goeie oorsig oor die verstaan van Psalm 110 in die vroeë kerk. By al die verskeidenheid in die 
verstaan van die Psalm, toon hy duidelik aan dat die vroeë Christene die Psalm gebruik het om die heerlikheid, die goddelike transendensie van Jesus, die Verlossingsmiddelaar, aan te dui. Dit is veral gebruik as 'n simbool van sy status (Hay 1973:155).

lets van die geskiedenis van die interpretasie van die Psalms in die vroeë kerk blyk uit die verskeidenheid van opskrifte wat by verskillende Psalms aangetref word in 'n belangrike Siriese Psalmmanuskrip uit die twaalfde eeu. Die manuskrip, bekend as 12t4 (vgl Van Rooy 1999:11-25, veral 21-25), het by elke Psalm minstens vier opskrifte. Een hiervan word aan die Hebreeus verbind, maar die ander drie word verbind aan die kerkvaders Athanasius, Eusebius en Theodorus van Mopsuestia. Enkele voorbeelde van opskrifte kan aantoon hoedat verskillende psalms Messiaans verstaan is. Al drie die kerkvaders se opskrifte vir Psalm 110 verbind die Psalm aan die Messias. Eusebius se opskrif is heel kort: Die oorwinning in die Messias. Die opskrif van Athanasius is baie langer, maar praat spesifiek van "ons Verlosser". Die opskrif van Theodorus maak die verbinding baie duidelik: "Hy (dit wil sê Dawid) profeteer oor die regering van ons Verlosser, die Messias." In die Oos-Siriese opskrifte, wat nou aansluit by die Psalmkommentaar van Theodorus, word vier Psalms as Messiaans aangedui, naamlik Psalm 2, 8, 45 en 110 (Bloemendaal 1960:22).

Dit is ook insiggewend om te kyk na die wyse waarop Calvyn Psalm 2 en 110 benader het. Hy verbind Psalm 2 primêr aan Dawid en trek dan van Dawid by wyse van tipologie 'n lyn na Christus. In die Latyn word vir Dawid as tipe die frase imago redemptoris gebruik (Calvyn 1887:43). Die vyande waarvan die Psalm praat, is Dawid se vyande (Calvyn 1845:9-10). Wat die gebruik van die woord Messias betref, sê Calvyn (1845:11) die volgende: "By honouring himself with the title of Messiah, or anointed, he declares that he reigned only by the authority of God, inasmuch as the oil brought by the hand of Samuel made him king who before was only a private person." Hy verbind dan wel hierna die Psalm aan Christus, deur te wys dat Dawid se koninkryk eintlik maar net 'n skaduwee is van wat sou kom. Die dinge wat Dawid oor homself sê, word met reg op Christus toegepas (Calvyn 1845:11). Van Psalm 2:7, waar die Ou Vertaling die woord "gegenereer" gebruik, sê Calvyn dat dit ten opsigte van Dawid wys na die dag waarop hy koning geword het (Calvyn 1845:17). Hy sê ook dat die gedeelte dikwels gebruik word om te dui op die ewige generasie van Christus, maar dat wat hom betref, dit eerder dui op die tyd toe dit aan die wêreld duidelik gemaak is dat Jesus die Seun van God is (Calvyn 1845:18). Dit is duidelik uit Calvyn se bespreking dat hy die Psalm nie as direk-Messiaans verstaan het nie, in die sin dat dit primêr in die oorspronklike konteks op Jesus Christus geslaan het. 
Daarteenoor is daar geen twyfel dat Calvyn (1847:294-295) Psalm 110 as direk Messiaans gesien het nie. Hy gee wel toe dat die dinge wat in die Psalm gesê word, tot 'n mate op Dawid toegepas kan word, soos byvoorbeeld dat vers 1 aandui dat Dawid regmatig op die troon gekom het. Tog kan dit wat die vers sê, nie in sy geheel en uitsluitlik op Dawid toegepas word nie (Calvyn 1847:297). In die res van sy kommentaar verbind hy die Psalm feitlik uitsluitlik aan Christus.

In van die besware wat teen die Nuwe Omdigting gestel word, word dit algemeen aangetref dat die Nuwe Omdigting aan 'n teologie verbind word "wat wesentlik van die Gereformeerde Skrifbeskouing afwyk" (d'Assonville, Kayayan \& Schulze 2004:32). Die kritiek aanvaar dus dat diegene wat minstens sekere Psalms nie as direk-Messiaans interpreteer nie, Skrifkrities is. Hieruit blyk dit duidelik dat hulle nie daarvan bewus is dat daar oor hierdie saak selfs tussen mense wat as "evangelicals" bekend staan, meningsverskil bestaan nie. Dit blyk uit 'n vergelyking van die standpunte oor hierdie saak van twee bekende Amerikaanse "evangelicals", Tremper Longman III en Walter Kaiser, sowel as uit die hele versameling van bydraes in 'n bundel met as redakteurs Satterthwaite, Hess en Wenham (1995).

Laasgenoemde bundel het begin by die werksaamhede van 'n jaarlikse byeenkoms van die Tyndale Old Testament Study Group, 'n groep wat tuis is in die kring van "evangelicals", 'n woord wat hulle self in die inleiding gebruik (Satterthwaite, Hess \& Wenham 1995:x). In 'n inleidende artikel in die bundel stel McConville (1995:2) dat die moderne (=kritiese) Ou-Testamentiese wetenskap daarvan uitgaan dat die tradisionele Messiaanse interpretasies van gedeeltes van die Ou Testament nie gehandhaaf kan word nie. Hy wys daarop dat dit inderdaad gebeur dat tekste wat in die Nuwe Testament op Jesus toegepas is, nie Messiaanse voorspellings is wanneer hulle in hulle OuTestamentiese konteks bekyk word nie. Hy verwys as voorbeeld na Hosea 11:1 (Uit Egipte het Ek my seun geroep), wat in Hosea op die uittog slaan en in Matteus 2:15 verbind word aan Jesus se terugkeer uit Egipte na sy verblyf daar saam met sy ouers (McConville 1995:13-14).

In die bundel is daar twee bydraes wat na spesifieke Psalms kyk. Johnston (1995) het 'n studie gemaak van Psalm 16 en Heim (1995) van Psalm 72. Johnston (1995:214) wys daarop dat Psalm 16:10 tradisioneel gesien is as ' $n$ voorspelling van Christus se opstanding uit die dood, maar dat dit deesdae eerder so gesien word dat die digter daarin sy vertroue uitspreek dat hy van die dood bewaar sal word. Johnston aanvaar self dat die digter se woorde spreek van 'n begeerte om van die doderyk bewaar te word, en dat juis hierdie begeerte spreek van 'n spanning wat eers in Christus opgelos word (1995:221-222). Op hierdie manier verstaan, is die betrokke vers nie 


\section{Die nuwe Psalmomdigting: Die Messias weggelaat?}

direk-messiaans nie, maar getuig dit van 'n spanning in die lewe van die gelowige, 'n spanning tussen lewe en dood wat eers in Christus opgelos word.

Heim (1995:248) se konklusie oor Psalm 72 neig in dieselfde rigting.

Die Psalm het in sy oorspronklike konteks nie dinge voorspel of verwagtinge geformuleer nie. Dit is ' $n$ voorbede vir die koning van daardie tyd. Tog is daar sekere elemente in die Psalm wat 'n Messiaanse herinterpretasie in later tye bevoordeel. Wat duidelik uit hierdie drie en die ander artikels in die bundel blyk, is dat mense binne die kring van die sogenaamde "evangelicals" nie almal maar bloot by die tradisionele interpretasie van messiaanse gedeeltes bly nie, maar dat sommige, met behoud van hulle evangeliese benadering tot die Bybel, die problematiek van die saak raaksien en ander oplossings soek wat reg laat geskied aan die tekste in hulle konteks in die Ou Testament, maar wat ook rekening hou met die manier waarop hierdie tekste in die Nuwe Testament aan die orde kom. Hierdie persone sal hulleself nooit beskou as in die kring van John Dominic Crossan en die sogenaamde "nuwe hervormers" nie (d'Assonville, Kayayan \& Schulze 2004:32).

As 'n laaste voorbeeld kan verwys word na die standpunte van Walter Kaiser en Tremper Longman III in hierdie verband. Hulle is beide bekendes binne die kringe van die "evangelicals" in Amerika. Kaiser se boek se titel (The Messiah in the Old Testament) wys reeds daarop dat hy in die lyn van die tradisionele interpretasie staan. Hy onderskei vyf en sestig direkte voorspellings van die Messias in die Ou Testament in die lig van sy eie skema van belofte en vervulling (vgl Kaiser 1995:240-242 vir 'n uiteensetting van die betrokke gedeeltes). Tog staan hy nie onkrities by die tradisionele benadering tot hierdie gedeeltes nie. In die inleiding van sy boek gee hy omvattend aandag aan die probleme in die verband en spel hy sy eie benadering uit.

Kaiser wys daarop dat die debat oor die interpretasie van die Messiaanse gedeeltes eintlik in alle erns begin het met die publikasie van twee boeke van Anthony Collins vroeg in die agtiende eeu, waarin die moontlikheid dat die betrokke Ou-Testamentiese tekste Messiaans is in die sin dat hulle direk op Jesus Christus van toepassing is, verwerp is (Kaiser 1995:13-14). Reeds in 1793 het Eichorn gesê dat die Messias uit die Ou Testament verwyder is (Kaiser 1995:19). Hierteenoor het Hengstenberg vroeg in die negentiende eeu gesê dat die Nuwe Testament die finale arbiter behoort te wees (Kaiser 1995:20).

Teenoor hierdie en ander metodes om die Messiaanse gedeeltes te behou, stel Kaiser twee basiese uitgangspunte vir die Messiaanse verstaan van gedeeltes in die Ou Testament: (1) Die betekenis van die OuTestamentiese verwysings na die Messias moet die skrywer se eie tyd en historiese omstandighede reflekteer, en (2) die betekenis is ' $n$ betekenis wat 
gereflekteer word in die grammatika en sintaksis van die Ou-Testamentiese teks (Kaiser 1995:23). Hy aanvaar dus 'n enkele betekenis van die OuTestamentiese tekste, waar hy sê dat die woorde van die skrywers van die Skrif se betekenis verstaan moet word volgens die normale spreektaal in soortgelyke kontekste in daardie tyd (Kaiser 1995:25). Hy aanvaar wat hy noem 'n "epigenetical meaning" (Kaiser 1995:24). Volgens hom maak hierdie benadering erns met sowel die historiese omstandighede waarbinne die woord oorspronklik uitgespreek is, en die voorspellende moontlikhede van daardie woord. Dieselfde woord kon dus tot die nabye en die verre toekoms spreek. Hy sê verder dat die debat oor die Messiaanse gedeeltes vasgeval het in die vraag of die oorspronklike konteks van die Ou-Testamentiese skrywer of die Nuwe-Testamentiese vervulling beklemtoon moet word (1995:27). Om die Nuwe Testament in die Ou Testament in te lees is vir hom eisegese (Kaiser 1995:27). Hy wil eerder praat van beloftes as van voorspellings (1995:28-29) en verbind die leer oor die Messias aan God se raadsplan wat deurloop na die Nuwe Testament toe (Kaiser 1995:31). Omdat daar ' $n$ belofte is wat algaande deur die Ou Testament ontwikkel, kan 'n spesifieke belofte dus ook meer as een vervulling hê. In die lig van sy uitgangspunte is Psalm 2 en 110 vir hom duidelike direkte Messiaanse Psalms. In sy bespreking van die twee Psalms word hulle ook direk aan die Messias verbind, sonder enige poging om 'n boodskap binne die tyd van die Ou Testament daarin te vind (Kaiser 1995:94-99).

Longman se siening van die Messiaanse Psalms verskil radikaal van Kaiser se siening. Hy stel dit baie sterk (1988:73): "Messianic Psalms, in an excusively narrow sense, do not exist." Daarmee ontken hy egter nie dat die Ou Testament op Jesus betrekking het nie. Vir hom is Jesus die fokuspunt van die Bybel as geheel (Longman 1988:65). Die term "Messiaanse psalm" kan volgens hom op twee maniere gebruik word. As 'n Messiaanse Psalm gesien word as 'n Psalm wat die Messias antisipeer, is alle Psalms volgens hom Messiaans. 'n Direkte Messiaanse Psalm sou vir hom een wees wat alleen maar die Messias voorspel en wat nie 'n direkte boodskap vir die OuTestamentiese periode gehad het nie (Longman 1988:67). 'n Basiese fout is om in die lees van 'n spesifieke Psalm die Ou-Testamentiese konteks te ignoreer (Longman 1988:73).

Wat uit hierdie bespreking duidelik is, is dat dit simplisties is om die ontkenning dat 'n sekere Psalm direk-Messiaans is, te koppel aan die Skrifbeskouing wat blyk uit die werk van Crossan en die sogenaamde "nuwe hervormers". Calvyn met sy lesing van Psalm 2, Tremper Longman en die skrywers van die bundel geredigeer deur Satterthwaite, Hess en Wenham (1995) sou dan almal in daardie kategorie moet val. 
Die gesindheid wat geleef het by diegene wat aan die Nuwe Omdigting gewerk het, blyk duidelik uit 'n artikel van die voorsitter van die interkerklike kommissie wat aan die Nuwe Omdigting gewerk het (Barnard 2000). Hy stel dit duidelik dat die Psalmbundel deur die Heilige Gees geïnspireer is (Barnard 2000:215), en dat die inhoud en bedoeling van die Psalms na hulle wesentlike inhoud en na hulle diepste betekenis in Jesus na hulle ware bestemming gekom het (Barnard 2000:216). Sy woorde aan die einde van die artikel vat dit alles mooi saam (Barnard 2000:226): "Ons sing egter die berymde Psalms ter ere van die God van die verbond, die verbond wat in Christus vernuwe is, en die God wat die Vader van ons Here Jesus Christus is, en deur Hom, ook ons Vader geword het."

\section{DIE BESWAAR GEWEEG}

Uit die voorafgaande bespreking is dit duidelik dat die saak van die Messias in die Psalms al baie lank bespreking ontlok en dat dit nie maar met 'n simplistiese beroep op die Nuwe-Testamentiese gebruik van die Psalms afgemaak kan word nie. Van die kritiekpunte in punt 2 vermeld, berus ook op 'n baie oppervlakkige lees van die Nuwe Omdigting. So verwys sowel d'Assonville (2002a) en d'Assonville, Kayayan en Schulze (2004) na die weglating van Psalm 31:6 in die Nuwe Omdigting. Dit is natuurlik 'n belangrike vers, omdat dit in die Nuwe Testament deur Jesus aangehaal word as een van sy kruiswoorde. Diegene wat beweer dat die vers weggelaat is, het egter nie die Nuwe Omdigting behoorlik gelees nie. Die eerste reël van strofe 2 sê: "Ek stel my in u hand vir leiding." Indien die vorige en daaropvolgende strofes goed gelees word en met die oorspronklike vergelyk word, is dit duidelik dat hierdie reël die beryming is van die gedeelte uit vers 6 wat weggelaat sou gewees het. Deur die betrokke vers in Psalm 31 wil die digter sy vertroue uitspreek dat die Here hom in die lewe sal hou en dat hy daarom homself aan die Here oorgee. Jesus gebruik die woorde egter met betrekking tot sy dood.

In die kritiek op die Nuwe Omdigting neem Psalm 2 en 110 'n besondere plek in. Dat die twee Psalms al lank as Messiaans beskou is, is algemene kennis. Dit is ook die standpunt van Kaiser, waarna bo verwys is. Wat Psalm 110 betref, kan verwys word na die artikels van Paul (1987) en Davis (2000) wat die Messiaanse interpretasie van die Psalm onderskryf. Davis (2000:173) is oortuig dat die inhoud van die Psalm aandui dat die Psalm suiwer Messiaans is, iets wat onderskryf word deur die NuweTestamentiese skrywers. Paul (1987:195) wys daarop dat baie skrywers Psalm 110 klassifiseer as 'n koningspsalm, wat dan later Messiaans gelees is. Volgens hom wys die Psalm na iemand wat sowel koning as priester is. In die geskiedenis van Israel was daar nooit so 'n koning nie. Daarom moet dit 
verwys na so 'n persoon wat nog sou kom, en dit kan alleen die Messias wees (Paul 1987:202). Beide die persone bespreek hulle standpunt op 'n wetenskaplike manier, en dit is standpunte waarmee ' $n$ mens inderdaad in gesprek sal kan tree. Dit is uiteraard onmoontlik om hier die twee Psalms in detail te bespreek. Wat hierop volg, is ' $n$ weergawe van die redenasie wat ten grondslag van die Nuwe Omdigting se hantering van die twee Psalms gelê het.

Beide die 1933/53-Vertaling en die 1936-Psalmberyming het Psalm 2 en 110 Messiaans verstaan. Die vergelyking van die twee vertalings en berymings van Psalm 2 in punt 2 het dit duidelik getoon. Die gebruik van die hoofletter by vers 2 en die ooreenstemmende gedeelte in die Beryming maak dit duidelik dat die ouer vertaling en beryming die Psalm direk-Messiaans verstaan het. Die nuweres het dit nie gedoen nie. Die feit dat die teks in Handeling 4:26 wel aan die Messias verbind word, kan nie die deurslag gee nie, soos bo geblyk het uit die bespreking van Kaiser se standpunt. Daar is baie Psalms wat in die Nuwe Testament aan die Messias verbind word en wat ook nie in die ouer vertaling en beryming direk-Messiaans weergegee is nie. Psalm 69:5 en 10 word byvoorbeeld in Johannes 15:25 en 12:17 aan Jesus verbind, maar die ouer vertaling en beryming het dit nie direk-Messiaans weergegee nie. Die 1983-vertaling en 2001-omdigting verstaan Psalm 2 só dat dit in die eerste plek geslaan het op die koning uit die geslag van Dawid, wat op Sion gesalf is (vers 6) en met wie die Here 'n vader-seunverhouding gehad het, soos wat die Here aan Dawid beloof het in 2 Samuel 7:14. Dit is natuurlik maklik om die lyn te volg van die koning uit die huis van Dawid na die Messias wat sou kom en daarom is ' $n$ tweede vervulling van die Psalm in Jesus Christus voor die hand liggend.

Wat Psalm 110 betref, is veral die beginwoorde geneig om gemoedere gaande te maak. Die 1933/53-vertaling het dit so weergegee: "Die HERE het tot my Here gespreek". Die teks word dikwels in die Nuwe Testament aan Jesus verbind. Die woord wat met "Here" vertaal is, is nie 'n Godsnaam in die Hebreeus nie. In die Hebreeus staan nie "Adonai" nie, maar "Adoni", 'n woord wat dikwels gebruik word om 'n mens van hoër rang aan te spreek. So gebruik Dawid die woord as hy Saul aanspreek in 1 Samuel 24:9, en hy noem Saul ook die gesalfde van die Here in 1 Samuel 24:7. In die Griekse vertaling van die Ou Testament - en dus ook in die Nuwe-Testamentiese aanhalings van die vers - word dieselfde woord gebruik vir drie woorde wat in die 1933/53-vertaling op drie maniere weergegee word: "HERE", "Here" en "my heer". Psalm 110 kan ook verstaan word as dat dit in die oorspronklike konteks gedui het op die koning uit die huis van Dawid, en weer kan 'n mens 
maklik van daar af die lyn volg na Jesus Christus toe, soos wat die Nuwe Testament inderdaad doen.

Deur die Psalms nie as direk-Messiaans te verstaan nie, trek die Nuwe Omdigting nie 'n streep deur die moontlikheid om die lyn na Christus toe te volg nie, maar hy begin met wat die Psalm in die oorspronklike konteks wou sê. In eksegese en prediking sal die lyn na Christus toe, en die Nuwe Testament se hantering van die Psalm, aan die orde moet kom. Dit is egter nie die taak van 'n psalmberyming (of 'n Bybelvertaling) om al daardie sake in die beryming in te werk nie.

\section{KONKLUSIE}

Die Nuwe Omdigting van die Psalms was 'n besondere baken in die geskiedenis van die Afrikaanse kerklied. Enige beryming bly mensewerk, en daarom is kritiek inderdaad altyd moontlik. Die beswaar dat die Nuwe Omdigting die Messias (of vir Christus) uit die Psalms weggelaat het, is egter nie geldig nie. In die nuwe Psalmboek van die Gereformeerde Kerke is daar by 'n aantal Psalms voetnote geplaas met verwysings na gedeeltes in die Nuwe Testament waar die Psalm aangehaal word. Dit kan die gebruiker van die Psalmboek help om die intertekstuele verbande beter raak te sien.

\section{Literatuurverwysings}

Barnard, A C 2000. Die besondere betekenis van die Psalms in die Christelike Kerk. Skrif en Kerk 21(2), 214-227.

Bloemendaal, W 1960. The headings of the Psalms in the East Syrian Church. Leiden: Brill.

Calvyn, J 1845. Commentary on the Book of Psalms, Vol 1, tr by J Anderson. Edinburgh: Calvin Translation Sociey.

Calvyn, J 1847. Commentary on the Book of Psalms, Vol 4, tr by J Anderson. Edinburgh: Calvin Translation Society.

Calvyn, I 1887. Commentarii in librum psalmorum pars prior: Ps. I ad XC. (Corpus Reformatorum LIX.)

d'Assonville, V E 2002a. Die nuwe Psalmberyming 2001. Weglatings en afwykings van die Hebreeuse teks. Waarheid \& Dwaling 8(2), 4-6.

d'Assonville, V E 2002b. Skrifgesag - Christus - Die Psalmberyming 2001. Waarheid \& Dwaling 8(5), 3-6.

d'Assonville, V E 2004. Die stryd rondom die suiwer Psalmboek. Stellenbosch 1812 Rustenburg 1859 - Potchefstroom 2003. Die Kerkpad 8 (1).

(http://www.kerkpad.co.za /januarie2004 /art3.html)

d'Assonville V E (jnr), Kayayan, E \& Schulze, L F. 2004. Christus self is in gedrang. Die Kerkblad, Maart, 32-33.

Davis, B C 2000. Is Psalm 110 a Messianic Psalm? Bibliotheca Sacra 157, 160-173. Haasbroek, D 2003. Is Jesus in die Psalms? D H Trust: Meyerton.

Hay, D M 1973. Glory at the right hand: Psalm 110 in Early Christianity. Nashville, TN: Abingdon. (SBL MS 18.) 
Heim, K 1995. The perfect king of Psalm 72, Satterthwaite, Hess \& Wenham 1995: 223-248.

Johnston, PS 1995. "Left in Hell"? Psalm 16, Sheol and the Holy One, in Satterthwaite, Hess \& Wenham 1995:213-222.

Meijer, JG 2002. Mag gereformeerde kerke die nuwe psalmberyming aanvaar? Waarheid \& Dwaling 8(2), 7-10.

Kaiser, W C (jr) 1995. The Messiah in the Old Testament. Grand Rapids, MI: Zondervan. (Studies in Old Testament Theology.)

Longman III, T 1988. How to read the Psalms. Downers Grove, IL: InterVarsity. McConville, J G 1995. Messianic interpretation of the Old Testament in modern context, in Satterthwaite, Hess \& Wenham 1995:1-18.

Momberg, H 2004. Vrae oor die teologie binne die GKSA. Die Kerkblad, Januarie, 26-27.

Paul, M J 1987. The order of Melchizedek (P 110:4 and Heb 7:3). Westminster Theological Journal 49, 195-211.

Satterthwaite, P E, Hess, R S \& Wenham, G J 1995. The Lord's annointed. interpretation of Old Testament Messianic texts. Grand Rapids, MI: Baker.

Van der Dussen P E 2004. 26 Oktober 2003: Dag van beslissing in die GKSA. Die Kerkpad 8 (1). (http://www.kerkpad.co.za/januarie2004/art4.html)

Van Rooy, H F 1999. Studies on the Syriac Apocryphal Psalms. Oxford: University Press. (JSS Suppl 7.) 